\title{
Characterisation of coking activity during supercritical hydrocarbon
}

\section{pyrolysis}

\author{
Nicolas Gascoin $^{\text {a* }}$, Philippe Gillard ${ }^{\mathrm{a}}$, Stéphane Bernard ${ }^{\mathrm{a}}$, Marc Bouchez ${ }^{\mathrm{b}}$ \\ ${ }^{a}$ Laboratoire Energétique, Explosion, Structure, UPRES-EA 1205, \\ 63, avenue de Lattre de Tassigny, 18020 Bourges Cedex, France \\ ${ }^{\mathrm{b}} \mathrm{MBDA}$ France \\ 8, rue Le Brix, 18000 Bourges, France
}

\begin{abstract}
The active cooling of the Supersonic Combustion Ramjet engine, for hypersonic flight purpose, is ensured thanks to fuel, n-dodecane for the present study. The endothermic fuel pyrolysis, starting above $800 \mathrm{~K}$, could generate an unwanted coke formation. Experimental tests up to $1125 \mathrm{~K}$ and between $1 \mathrm{MPa}$ and $6 \mathrm{MPa}$ have been performed on the hydrocarbon fuel pyrolysis to evaluate the coking activity. $316 \mathrm{~L}$ stainless steel, low carbon steel and titanium reactors have been considered. A witness of the coke formation, based on its thermal insulation and pressure loss effects, has been found. A correlation between methane production and coke deposit was found. The coke has been studied with Scanning Electron Microscope (SEM), Energy Dispersion Spectroscopy (EDS), X-ray diffractometer and Fourier Transform Infrared (FTIR) spectroscopy. The porosity, the density and the permeability of the coke have been estimated.
\end{abstract}

\section{Keywords}

Coke, hydrocarbon pyrolysis, supercritical state, catalytic effect, dodecane.

\section{Introduction}

* Corresponding author. Tel.: +33.248.238.473; fax: +33.248.238.871. E-mail address: Nicolas.Gascoin@bourges.univ-orleans.fr (N. Gascoin) 
A hypersonic flight [1] [2] is expected to be achieved with dual-mode-Ramjet, i.e. Ramjet under Mach 6 and Supersonic Combustion Ramjet (SCRamjet) beyond [3] [4], because of its high specific impulse and its capability to be reusable [5] [6]. The total temperature of the outside air reaches temperatures as high as $4950 \mathrm{~K}$ for example at Mach 12 and even composite materials could not withstand such a large heat load. Thus, an active cooling system has to be used but not a dedicated one in order to avoid overweighting the vehicle. Furthermore [7], the time allocated to mix the injected fuel with incoming air, to ignite the combustion and to complete it before the chamber outlet is about $10^{-3} \mathrm{~s}$. These two points lead to use the fuel to cool down the engine's wall and then to burn it in the combustion chamber. Different cooling strategies have been evaluated by the MBDA-France company and its partners with calculations [8] and material tests [9]-[11]. The principle of SCRAMJET technology, its advantages, and the interest to use hydrocarbon fuel to cool down the engine have been fully studied in the literature [12][15]. Compared to cryogenic hydrogen, heavy hydrocarbon fuels are safer, much simpler to use, their costs are lower and they conduct to smaller vehicles because their density is higher than that of cryogenic fuels.

The present work falls within the framework of the COMPARER project (a French acronym for COntrol and Measure of PArameters in a REacting stream). It aims at studying the following cooling strategy, using as a first step the n-dodecane for the endothermic fuel [16]. Liquid n-dodecane is injected near the outlet of the combustion chamber in a composite channel [10] which surrounds the engine. It flows to the injection in counter-flow to the burned gases. When heated above $800 \mathrm{~K}$, the fuel is pyrolysed and thanks to its endothermic behaviour, it ensures the active cooling of the hot combustion chamber walls. This pyrolysis produces lighter hydrocarbons species such as hydrogen and ethylene, which have shorter ignition delay. This allows to respond to rapid phenomena inside the combustion chamber. It is important to note that the expected high pressure in the cooling loop ( $>3 \mathrm{MPa}$ ) causes the fluid to become supercritical in the channel, which leads to some difficulties such as fluid properties evaluation and flow rate measurement.

The mass flow rate injected in the combustion chamber is expected to be slightly lower than the one pumped from the tank because of the film cooling due to porous walls and because of carbon deposits due to coke formation. This last phenomenon will also change the carbon/hydrogen ratio of the fuel in the channel. It needs to be studied because it influences the combustion and the thrust. Furthermore, the 
coking activity could disturb the cooling because of jamming. For example, a typical stainless steel reactor, used on the experimental test bench presented in this paper, is completely jammed by coke after five hours at $1000 \mathrm{~K}$ with a flow rate of $0.05 \mathrm{~g} \cdot \mathrm{s}^{-1}$. The chemical reactor has an internal diameter of 4.5.10 $10^{-3} \mathrm{~m}$. It has to be noticed that it is expected to have a similar mass flow rate on cross-section ratio for the SCRamjet. The typical flight time should be about 20 minutes and the cooling channel is planned to be in a carbon-based composite material.

The aim of the COMPARER project is to identify some relevant parameters in order to propose and to evaluate measurement methods. These ones have to be suitable for onboard and real-time application on supercritical multi-species mixture $(6 \mathrm{MPa}, 1500 \mathrm{~K})$. The latest should allow regulating the cooling and controlling the engine depending on chemical composition characteristics as well as mass flow rate. This implicates to study the coupled phenomena involved in the pyrolysis.

A review of SCRamjet activities has been done to determine if some of them are related to the identified need. The facilities requirements for ground or in-flight tests appear to be very heavy [17] [18] and modelling is a more feasible method to conduct engineering studies and to further research related to this topic [19]-[22]. Some experimental studies are available on hydrocarbon pyrolysis for cooling purpose [23] [24]. They mainly focus on the production and the consumption of species following various parameters, such as the mass flow rate and the operating pressure or temperature. They aim at understanding the pyrolysis process and they often try to study the pyrolysis under conditions, which limit the coke formation (temperatures lower than $1000 \mathrm{~K}$, low residence time, low catalytic effect of reactor material) in order to have stable test conditions.

In previous papers [25], it has been shown for this purpose the need to use high operating temperature, up to $1500 \mathrm{~K}$. This allows to produce interesting species for the combustion, such as hydrogen and ethylene. These ones are highly hydrogenated species (with a Hydrogen/Carbon mass ratio of respectively infinite and 0.25 ) compared to initial $\mathrm{n}$-dodecane ( $\mathrm{H} / \mathrm{C}$ ratio of 0.15$)$. Nevertheless, this is accompanied by a corresponding high coke production (lowly hydrogenated). This needs to be understood rather than avoided. This should be done in relation to chemical kinetics of the n-dodecane pyrolysis. For example, it is well-known that acetylene is a first step for the benzene production during the coke formation process. But this kind of accurate study is a very challenging work considering the actual knowledge on the topic, due to complex coupled phenomena. It has been preferred here to use a macroscopic approach to provide 
useful data and to manage the coke activity rapidly.

Several studies are available in the literature about coke formation even if they are not specifically oriented for engine cooling of air-breathing hypersonic propulsion. This topic is studied due to its harmful consequences in petrochemical process, in particular the hydraulic jamming and the thermal insulation of the pyrolysis channel. Several origins can explain the coke formation. At low temperatures, if some oxygen is present in the fluid, the oxidative coke should be predominant [26]. But we plan to use deoxygenated fuel in our project (concentration of oxygen about few part per million -ppm-), so this type should not appear in the study [27]. At higher temperatures, the coke is mainly pyrolytic [28] because of the thermal cracking of hydrocarbon. It is due to the formation of acetylene, benzene and then polyaromatic hydrocarbons $(\mathrm{PAH})$. This coke probably differs from the pyrocarbon as it is obtain in a high pressure flow contrary to pyrocarbon [29]. A catalytic coke is also formed due to the material nature of the chemical reactor [30]. The chemical formation of this one and its characteristics depend on the components of the reactor material. This coke should sticks to the inner surface of the chemical reactors because it starts appearing in the roughness of the reactor. It has to be noticed that the reactivity of the reactor decreases slightly when the carbon deposit increases because this one deactivates the support [31]. When the pyrolysed fluid is cooled down, an asphaltic coke can also appear [32]. It is due to the condensation of heavy polyaromatic hydrocarbons (PAH) and it can be found in the downstream part after the furnace. The asphaltic coke appears mainly for heavy initial hydrocarbons and not for the ethane for example. For these four types of coke, the chemical compositions are different (from pure carbon to heavy PAH with several cycles). Various structures, from amorphous to tubular or filamentous ones, have also been identified in the literature, depending on the pyrolysis conditions [30]. Cai et al. [30] identify a filamentous structure for catalytic coke and consider it as a precursor for amorphous pyrolytic coke. This conducts to heterogeneous reactions between solid and gas. The coke formation has been widely studied [28]-[38] and chemical reaction pathways are also proposed, depending on the conditions [30]-[41]. Chemical reactions, such as dehydrogenation, isomerisation and cyclisation, are identified in the coke formation.

Various parameters can influence the coke formation : the temperature [28] [40], the pressure [42], the physical state of the fluid [36] [41], the material nature of the reactor [28], the residence time in the process [28] [42] [40], the dilution and the pyrolysis rate [28], the flow turbulence [32], the presence of 
dissolved impurities [43], the presence of colder parts in the process [32]-[34] and the combined effect of applied heat flux and residence time [44]. It has to be noticed that for some rare specific cases, a moderate heat flux applied on the fluid could provide more carbon deposit than high temperature if the fluid is not completely evaporated [43]. Some numerical studies are also available on coke formation but these can only be applied to the specific conditions for which the mechanisms of reactions have been designed [45][47].

In general, the conditions of coke formation are mostly well-known and well studied but the studies are almost impossible to extrapolate to conditions other than the ones of study. The purpose of the COMPARER project is to study the pyrolysis of n-dodecane and to evaluate some measurement methods to characterise the phenomena. The coking activity needs to be studied because it is a part of the pyrolysis process but it remains an unwanted part. Seeing that we do not planned to change the pyrolysis conditions to avoid the coke formation, we try to characterise the carbon deposit. What we want is to understand and control the coke formation without limiting it with specific additive [48] [49].

A numerical tool, called RESPIRE (a French acronym for SCRamjet Cooling with Endothermic Fuel, Transient Reactor Programming) has been developed for the COMPARER project [50]. It uses a detailed pyrolysis mechanism (1185 reactions, 153 species) and it is adapted to stationary and transient studies under liquid, gas or supercritical conditions. Nevertheless, it is not adapted for this study because it does not consider the coke formation.

The aim of this paper is to provide an applied approach to characterize the carbon deposit in order to prevent its formation, to monitor it, to decrease its harmful consequences and to evaluate them from a hydraulic point of view. The surface roughness effect is not studied in this paper even if it is known that the coke formation depends on the open porosity of the material [40] [42] [51]. Furthermore, it appears that the carbon deposit rate found in various studies of the literature could not be extrapolated to our case. Indeed, various coking rate are related in some studies [48] [52] for given test conditions but a 1000 factor appear between all the numerical value depending on the conditions. The values are not reliable to use them in our project.

We will present in this paper a physical and chemical characterization of the coke deposit, such as a visualisation depending on the test conditions. The parameters that influence the coke formation will be examined. Then we will show how the coking activity can be detected during the pyrolysis process and 
how these observations can help to prepare a measurement method for carbon deposit monitoring. For this study, we do not separate coke from tar and we consider them indifferently.

\section{Presentation of the experimental test bench and measurement instruments}

In the framework of the COMPARER project, a specific test bench has been designed to study the hydrocarbon pyrolysis under potentially supercritical conditions for steady-state and transient conditions. The experimental test bench has been described in a previous paper [53]. It aims at providing: understanding of the coupled phenomena, validation data for the numerical code RESPIRE and evaluation of onboard and online measurement methods for industrial use. The conception of the experimental apparatus has been based on the SCRamjet's operating conditions (Figure 1). The cooling channel is represented by a chemical reactor, the thermal aspect of the combustion chamber by a furnace and the combustion of pyrolysis products by an academic burner. Predimensionning calculations have been performed to define the test bench, thanks to the CFD software Fluent and to the code Nancynetik, which has been used for previous studies [4]. The n-dodecane fuel, taken at ambient conditions, is injected in the chemical reactor thanks to a pump which is limited to a maximum working pressure of $10 \mathrm{MPa}$ and to a maximum mass flow rate of $0.6 \mathrm{~g} \cdot \mathrm{s}^{-1}$. The furnace, in which the chemical reactor is inserted, bears a maximum temperature of roughly $1850 \mathrm{~K}$. Pressure is regulated through an automatic valve controlled to vary the operating pressure in transient conditions. A Coriolis mass flow meter is available at the reactor inlet to measure transient mass flow rate and density.

After the regulation pressure valve, the fluid pressure is near the atmospheric one and the liquid phase of the cooled pyrolysed mixture is gathered in a dedicated phase separator. The gas phase is evacuated with a Bunsen burner. A specific instrumentation has been settled to characterise the phenomena and furnish suitable data for our purpose. A Gas Chromatograph (VARIAN, Star 3800) equipped with 10 sampling loops is used to analyse the gas samples taken at ambient conditions. Hydrocarbons, liquids at ambient conditions, are analysed thanks to a coupling Gas Chromatograph (AGILENT, 6850) - Mass Spectrometer (AGILENT, 5973). Liquid samples are collected during the pyrolysis at the phase separator inlet. The proportion of gas and liquid is measured at the outlet. The composition of the complete pyrolysed mixture is obtained thanks to the chemical analysis of both phases. The parameters of the study (temperature, pressure, mass flow rate) are transiently obtained through about forty simultaneous 
measures. To conduct the observations on the coke deposit, a Scanning Electron Microscope (LEO, modèle 1455 VP) is used. It allows conducting Energy Dispersion Spectroscopy (EDS) on the samples at an operating voltage of $10 \mathrm{kV}$. Furthermore, the crystallographic structure is given by an X-ray diffractometer (PHILIPS, X'Pert 1998) with $\mathrm{Cu} \mathrm{K}_{\alpha}$ radiation. FTIR measures are done thanks to a Nicolet 380 FTIR with Diffusive Reflectance accessory and Attenuated Total Reflectance (ATR). The FTIR peaks correspond to different modes of deformation for the chemical bonds. These ones can then be attributed to chemical compounds by comparison with database even if the FTIR is not the most appropriate tool to identify a component. An infrared camera has also been used (Flir Systems, Thermacam S45).

The results presented in this paper concern the coke deposits obtained at stationary state, under pressure from $1 \mathrm{MPa}$ to $6 \mathrm{MPa}$, at maximum fuel temperature from $650 \mathrm{~K}$ to $1125 \mathrm{~K}$ and for mass flow rates of $0.05 \mathrm{~g} . \mathrm{s}^{-1}$ and $0.1 \mathrm{~g} . \mathrm{s}^{-1}$. The chemical reactors are made of stainless steel $316 \mathrm{~L}$ (SWAGELOK), low carbon steel and titanium. Geometric data are given in Table 1. Some reactors with a lower diameter have been tested but their jamming up by the coke is encountered before the stabilisation of the system, which is needed to conduct stationary studies. The estimated chemical mass compositions of the three reactors are given in Table 2. Their physical properties are considered as not interfering in the pyrolysis results despite the density discrepancies. The densities are respectively $7950 \mathrm{~kg} \cdot \mathrm{m}^{-3}, 7870 \mathrm{~kg} \cdot \mathrm{m}^{-3}, 4500$ $\mathrm{kg} \cdot \mathrm{m}^{-3}$ and the thermal conductivities are $15 \mathrm{~W} \cdot \mathrm{m}^{-1} \cdot \mathrm{K}^{-1}, 20 \mathrm{~W} \cdot \mathrm{m}^{-1} \cdot \mathrm{K}^{-1}, 16 \mathrm{~W} \cdot \mathrm{m}^{-1} \cdot \mathrm{K}^{-1}$ at $293 \mathrm{~K}$.

\section{Characterisation of coke deposit on chemical reactors of various natures of materials}

The catalytic activity can differ from the material (the Nickel has a higher one than the Iron) and from its thermal or chemical treatment. For example, between $450^{\circ} \mathrm{C}$ and $650^{\circ} \mathrm{C}$, steel is transformed into cementite $\left(\mathrm{Fe}_{3} \mathrm{C}\right)$, which presents no catalytic effect in the hydrocarbon pyrolysis [54]. Polishing a surface favours the presence of Chromium atoms on the surface, which increases the catalytic activity of the tube [55]. Molybdenum, Nickel, Manganese and Potassium are known to play an important catalytic role [56],[57]. This catalytic effect also depends on the fluid composition: as an example [58], it plays a role in the n-hexane conversion and not in the benzene one for the same experimental configuration.

Furthermore, heating and cooling several times the same chemical reactor conducts to form an oxide film on the surface. The higher is the process temperature, the more discontinued is the oxide layer on the 
surface [59]. While increasing the process temperature over the cycles, the oxide phase is modified. In addition, the formation of hydrogen during the pyrolysis process carries to hydrogen permeation through the reactor. This is important to consider in presence of corrosion inside the reactor while oxidation of the reactor appears with the outside air [60]. It could modify the reactivity of the material. The velocity and the phase of the fluid flow inside the reactor can also have an impact, not necessarily linear, on the heterogeneous reactions between the solid and the fluid [61],[62]. The oxidation of the reactors between the tests favours its corrosion by the fluid during the test [63]. Consequently, it is difficult to know exactly, what is the composition of the material in contact with the fuel. The test conditions also greatly act on the reactions between the reactor and the fluid. This outlines why it is difficult to clearly provide a universal explanation of the phenomena observed during our tests.

\subsection{SEM observations, EDS, X-ray and FTIR analysis}

\subsubsection{Stainless steel reactors}

Thanks to SEM observations, coke deposits obtained with 316 L (ASTM) stainless steel reactors (Figure 2a) appear to be composed of millimetric aggregates constituted from micrometric particles (Figure 2b). Because no specific arrangement is found on the images for this type of coke, such as filamentous structure for example, it could indicate that it was formed mainly inside the fluid flow; probably starting from aggregation of condensed heavy PAH as it is related in [32]-[34]. The condensation of PAH favours the nucleation of carbon atoms. The same type of coke has been analysed downstream the process in a reduced section, which shows that this coke does not stick to the wall. So that, it could have been mostly produced in the fluid flow and not on the reactor surface, which would be the result of catalytic reactions [40] [42] [43]. Thus, this coke is assumed to be a mix of pyrolytic and asphaltic ones because these ones have been respectively found in the hottest part of the reactor, near the furnace middle, and also near the furnace outlet, where the temperature is decreasing near $600 \mathrm{~K}$. The high concentration of Nickel and Chromium in the stainless steel should favour the production of catalytic coke. It is thus difficult to evaluate the contributions of these three kinds of coke in the final deposit.

The strong hydrocarbon smell could indicate a high proportion of PAH (even if the nose remains a very poor analyses tool). Nevertheless, the first FTIR-ATR measures did not provide any information on this point. This is attributed to the evaporation of odorous volatile substances during the laps of time between the experiments and the analysis. This has been confirmed latter by second analyses of the coke, 
taken out from the chemical reactor. Even after few months in the reactor under ambient conditions, the HAP remains trapped. It has to be noticed that the strong aromatic smell decreases with time since this coke was less odorous than the first one just after the experiment. The second sample has then been observed by FT-IR (Figure 3). A strong similarity was found with Aromatic Hydrocarbon Resin (Hummel Polymer Sample Library, index 37), which confirms the presence of HAP. The peak near 2350 $\mathrm{cm}^{-1}$ is due to the bad consideration of $\mathrm{CO}_{2}$.

X-ray analyses have also been performed on the coke deposit (Figure 4). A specific crystallographic structure has been revealed. It corresponds to the magnetite $\left(\mathrm{Fe}_{3} \mathrm{O}_{4}\right)$ that shows an oxidation of Iron particles inside the sample during the time length between the experiments and the X-ray measures. No carbon based structure has been found, which confirms that the coke should have been heterogeneously produced in the flow. EDS measurements have shown a high Chrome content (up to $13 \%$ in mass for 80 $\%$ of carbon). Nickel has also been found in quantities smaller than one percent. This is consistent with the stainless steel composition and it is a sign that a corrosion of the reactor appears during the fuel pyrolysis. The corrosion of the tube may have decreased its catalytic effect. Nevertheless, a strong heterogeneity has been found between the aggregates, probably because of their way of production. The maximum concentration of carbon is about $94 \%$, with $4 \%$ of Iron. Some other elements have been found such as $\mathrm{Ca}, \mathrm{Si}, \mathrm{Al}$ but this is attributed to contamination of samples, even if Cai et al. [30] also noticed these compounds without giving any explanation about their origin. Oxygen has also been found in metallic oxide but this is probably due to oxidation of the sample during the few months between the experimental tests and the measures.

A test has been conducted on some 316 L reactors, completely jammed by coke, to evaluate the coke permeability. The coke thickness in the flow direction, which corresponds to the length of the jam, is estimated to be of $5.10^{-3} \mathrm{~m}$. This is the maximum length observed on opened tube samples after jamming up (Figure 5). Pure n-dodecane, at ambient temperature, has been used at three pressures (1 MPa, $3 \mathrm{MPa}$, $5 \mathrm{MPa})$ for three different mass flow rates $\left(17 \cdot 9 \cdot 10^{-3} \mathrm{~g} \cdot \mathrm{s}^{-1}, 61.10^{-3} \mathrm{~g} \cdot \mathrm{s}^{-1}, 90 \cdot 7 \cdot 10^{-3} \mathrm{~g} \cdot \mathrm{s}^{-1}\right)$. The pressure losses $(\Delta P)$ have been measured under stationary conditions (Figure 6). Knowing the mass flow rate $(\dot{m})$ and thanks to the Darcy Law (Eq. 1), it is possible to obtain the ratio $\frac{\kappa}{e}$ (the coke permeability divided by its thickness). Consequently, the value of $\kappa$ is calculated, $4,6.10^{-8} \mathrm{~m}^{2}$, with a coke length of $5.10^{-3} \mathrm{~m}$ as stated above. This value has to be compared to the one of engine's porous walls, relatively lower than $10^{-}$ 
${ }^{15} \mathrm{~m}^{2}$. This highlights the fact that the coke is largely porous and if this one occurs, the fluid should continue to mainly flow through the channel and not directly from the channel to the combustion chamber through the porous walls.

$$
\dot{m}=\frac{\Delta P \times \frac{\kappa}{e} \times A}{\frac{\mu}{\rho}}
$$

with $A$ the cross-section, $\mu$ the dynamic viscosity and $\rho$ the density that are chose for pure n-dodecane at ambient temperature and operating pressure.

The density of the coke aggregates has been estimated thanks to a mass balance (Sartorius, range of $30 \mathrm{~g}$ with $0.01 \mathrm{mg}$ of accuracy) and a glass picnometer. Measurements have shown a density of about 560 $\mathrm{kg} . \mathrm{m}^{-3}$. If we consider as a first approximation that the coke is composed of pure carbon, this gives a porosity of more than $70 \%$. This result is in qualitative agreement with the high permeability and the preceding SEM observations that previously conducted to estimate that the coke has been formed along the fluid flow. In addition, this high porosity favors the volatility of HAP and this can explain why the HAP could not have been detected by FT-IR after a long time between experiments and analyses. Characterizing the aggregates is useful, particularly to evaluate the possible jamming up of the millimetric injectors. It is now estimated that the coke particles are small enough to avoid such a problem as filling up.

\subsubsection{Steel reactors}

Coke deposits obtained with low carbon steel reactor in the same operating conditions as for 316L reactor have shown a totally different structure when observed with SEM visualisations (Figure 7a). It is attributed to the low concentrations of chemical elements such as Nickel or Chromium, which have a high catalytic effect on the hydrocarbon pyrolysis. The deposit appears as very dry shavings of about $15.10^{-6} \mathrm{~m}$ thick, with no particular smell. Some coke has also been found downstream the furnace but under a very dry powder form. The shavings stick quite well to the reactor surface. On its outer surface, which corresponds to the inner reactor surface, some ridges can be identified (Figure 7b). These correspond to the reactor conception, obtained by lamination. Due to its high adhesion, it is assumed that a first layer of catalytic coke appears. This should be formed in the roughness of the material. Because of the high Iron concentration of the tube, the steel may transform into cementite at temperature for which the stainless 
steel is not modified $\left(450^{\circ} \mathrm{C}-650^{\circ} \mathrm{C}\right)$. The catalytic effect is then deactivated, which explain the low coking activity of the low carbon steel. This first coke layer may then favour the accumulation of pyrolytic coke. Furthermore, it appears at a temperature lower than for stainless steel reactor. Because of the very dry coke and the neutral smell, it is assumed few asphaltic coke is produced.

If this kind of identified coke appeared on the SCRamjet engine, it would not be a problem for the jamming up of the channel and of the millimetric injectors because it would stick to the wall. This could be checked under high vibrating conditions.

The density of the dry shavings has also been estimated on three different samples thanks to mass measurements. The three values correspond to a mean value of $1883 \mathrm{~kg} \cdot \mathrm{m}^{-3}$. The volume of the shavings has been determined for hollow cylinder with an estimated thickness of $15.10^{-6} \mathrm{~m}$ (based on MEB images) and with the length of the observed samples. Considering the coke to be composed of pure carbon (density around $2000 \mathrm{~kg} \cdot \mathrm{m}^{-3}$ ), this conducts to determine a coke porosity of about $(2000-1883) / 2000=6 \%$. This result is in qualitative agreement with the SEM observations of dry and compact shavings.

The coke deposit, observed with FTIR-ATR, presents a signal similar to Aromatic Hydrocarbon Resin and to Hydrocarbon Resin, in accordance with public databases (Figure 3b). This is a surprising result because we did expect to find HAP in the asphaltic coke but not really in the pyrolytic one. The coke samples were previously mashed before the analyses by DRX and FTIR. The HAP were trapped inside the coke deposit because of its very low porosity. These volatile substances have been detected after mashing the deposit whereas, for the same conditions of handling, they were not in the sample anymore for odorous aggregates with high porosity. This could explain the dry shaving structure. X-ray analysis did not show a special crystallographic structure despite the particular shape of coke (Figure 4). The EDS measurement presents a carbon composition of almost $100 \%$ on the inner surface of the shavings, in contact with the fluid, whereas the outer surface contains about $90 \%$ of carbon. The other $10 \%$ are composed of metallic elements such as Iron, Molybdenum, Manganese, which are supposed to be extracted from the reactor walls, when the coke is removed, but not during the pyrolysis process. If the metallic species came from the tube corrosion during the pyrolysis, some should be observed on the inner surface of the shavings. This is not the case. Measurements have been done several times on various samples and all are consistent. This is an interesting point because it is in contradiction with the 
conclusions of Cai et al. [30] In their study, they show a major presence of metal particles (Iron, Chromium,...) on the face in contact with the fluid compared to the face of the carbon deposit in contact with the reactor. They assume that metallic elements come from reactor corrosion. None of Chromium or Nickel elements have been detected in our samples.

\subsubsection{Titanium reactors}

The discrepancies observed between the two kinds of steel (low carbon and 316L) cannot be attributed to a different thermal conductivity of the reactors walls. For example, variation of thermal conductivity should only shift the phenomena following the temperature but not change the coke characteristics. Thus, the catalytic effect of the reactors is implicated. The distribution of pyrolysis products [64], especially for the ethylene formation, shown strong variations depending on the catalytic effect of the reactor. Ethylene concentration raises a maximum of $35 \mathrm{vol} \%$ in the gas products in $316 \mathrm{~L}$ reactors whereas the maximum observed on Titanium or low carbon steel reactors is about 15 vol\%. To confirm this well-known catalytic behaviour, a test has been conducted with Titanium reactor, which is known for its lower catalytic effect. Its thermal conductivity is close to the one of steel reactors. The FT-IR analysis conducted on the coke (Figure 3c) does not show any particular signal. The peak near $2350 \mathrm{~cm}^{-1}$ is only due to the bad consideration of $\mathrm{CO}_{2}$. The coke shows a dry powder form, which may be characteristic of pyrolytic coke because the asphaltic one should look like the tar with a strong aromatic smell and the catalytic one should stick to the wall. Furthermore, the gain of mass with titanium tube due to the coke during a test, under fixed operating conditions, is about $0.1 \mathrm{~g}$ where it is about $0.3 \mathrm{~g}$ for the low carbon steel reactor and

$0.5 \mathrm{~g}$ for the stainless steel reactor. This result is very interesting because it shows that the coking activity could be drastically reduced by using reactor with low catalytic effect. This is encouraging for the engine because the walls are planned to be made in carbon composite material. This should have an even better behavior than Titanium, which will decrease the jamming up issues.

In addition, it could be interesting to evaluate the coking activity of the three various phenomena. If we consider that the pyrolytic coke formation does not depend on the material nature of the reactor, it is possible to assume that the three reactors present the same quantity of pyrolytic coke : $0.1 \mathrm{~g}$. This is the mass observed on the titanium reactor, and for which we estimate that asphaltic and catalytic coke are not present. Then, the quantity of catalytic coke can be deduced from the carbon deposit obtained for low carbon steel reactor. This corresponds to $0.2 \mathrm{~g}$, which is about two times the quantity of pyrolytic coke. 
Finally, based on the stainless steel reactor results, the asphaltic coking activity could be about the same as the catalytic one. The activities of coke formation appear for our experiment to be in this order : Asphaltic $\geq$ Catalytic $\geq$ Pyrolytic with the following proportion : $40 \%, 40 \%, 20 \%$. So, the catalytic coke that appears because of the experimental reactor material nature, and the asphaltic coke, which appears because of colder parts in the process, are both predominant in the coking activity of the COMPARER test bench. They should not be a problem in the SCRamjet engine because they are due to causes that do not exist on the hypersonic vehicle. This study prefigures that the major problem for the vehicle will be the pyrolytic coke. This one is due to the pyrolysis process of hydrocarbon and in particular to cyclic compounds. We have shown during the experiment that the filling up of reactors by coke appears at almost $1025 \mathrm{~K}$ whereas at $925 \mathrm{~K}$, the process remains almost stable. It shows that it is not possible to limit the coke formation by limiting the temperature because this one is too low to be interesting for the cooling application. Thus, some additives (such as tetralin or decalin [24],[65]) may be used to decrease the coke formation. It would also be necessary to study the influence of the Reynolds number of the flow to see if a higher flow speed can limit the coke production but this would interact with the related residence time.

\subsection{Influent parameters on coking activity}

The following obvious parameters take part in the coke formation on quantitative or qualitative aspects:

- Heat flux density applied to the fluid

- Wall temperatures

- $\quad$ Fluid pressure

- Residence time

- Time length of the test and fluid quantity used during it

- Reynolds number of the fluid flow

- Catalytic effect of the reactor material nature

- Impurities dissolved in the initial fluid

The heterogeneous deposition of the coke along the reactor and the fact that the data used for this study have been mainly obtained during tests to study pyrolysis make the data's exploitation quite difficult, as well as the evaluation of the effects of the parameters. It has been chosen to use the gain of 
mass during a test to represent the coking activity. It should be interesting to link this activity to the pyrolysis rate but this has not been possible. The tests are conducted during hours at various conditions, thus with different pyrolysis rates from $0 \%$ to $100 \%$.

It has been previously verified that the gain of mass due to reactor oxidation in the ambient air inside the furnace is lower than $0.1 .10^{-3} \mathrm{~g}$ after three hours under $1000 \mathrm{~K}$. The gain of mass corresponds to the coke sticked to the wall. The one accumulated downstream, in the reduced cross-sections, is also measured and it is typically lower than $10 \%$ of the one deposed along the reactor. In the literature, the coking rate is often expressed in $\mu \mathrm{g} \cdot \mathrm{cm}^{-2} . \mathrm{s}^{-1}$. Consequently, this rate is expressed in our study by dividing the mass of coke by the inner surface of the one meter long reactor and by the time length of the pyrolysis test, for process temperature above $623 \mathrm{~K}$. It has to be noticed that the residence time is difficult to evaluate experimentally. Considering the entire inner surface is questionable because it does not correspond to temperatures compatible with the coke formation. For example, the reactor inlet temperature is lower than $500 \mathrm{~K}$. Furthermore, the coke deposition is not uniform all along the reactor. Nevertheless, this is a first approach to give reasonable results. This also allows comparing various pyrolysis tests by using the same reactor length, without studying in details the way of deposit.

All the study cases available for our study have been represented on the figure 8 for evaluation of the effect of the mean residence time on coking activity. The residence time has been estimated thanks to numerical simulations conducted with the RESPIRE code. It is the time needed for a particle to cover the reactor length. In fact, the residence time can be divided in three different times [64]. The first upstream part of the process is dedicated to the heating of the fluid, before the pyrolysis process. Secondly, the fluid is pyrolysed. Thirdly, it is cooled down in the downstream part of the furnace because the temperature decreases due to border effect. The residence time contains these three times.

A direct relationship appears between the coking rate and this residence time (Figure 8), considering a logarithmic scale. This highlights the high residence time dependence of the coke formation. The typical order of residence time in the cooling channel of the SCRamjet engine is about $1 \mathrm{~s}$. This allows thinking that the pyrolytic coke formation could be limited, compared to experimental conditions. Nevertheless, two other specific configurations also appear. One corresponds to a configuration without flow, where the residence time is the time length of the test; the other one to a reduced inner diameter of reactor. For the first one, the coke deposit rate is lower than the main test configuration because of strong thermal 
heterogeneity inside the reactor. The hottest part is much localised in the middle of the furnace. Because the second configuration is also much different, with a low residence time, this shows that another parameter is important in the coke formation. This could be the exchange surface between the fluid and the reactor or the fluid dynamics linked to the cross section.

We have formerly shown that methane (highly hydrogenated) formation is linked to the n-dodecane pyrolysis [64] and to the coke production (poorly hydrogenated). The mass of coke measured inside the reactor is linked to the methane production, integrated in term of maximum temperature noticed inside the furnace (Figure 9). To do so, the molar fraction of methane has been plotted as a function of furnace temperature and then integrated. All the data seem to follow a linear trend, except with the low carbon steel reactor. This shows that for the stainless steel reactor, the coking activity depends on the temperature of the process and it is intimately linked to the production of methane. This opens some way of study for the coke monitoring during the test and that will be detailed in the next section. The particular behaviour of the steel reactor shows the importance of catalytic effect of the material.

Furthermore, the fluid quantity used during the test, as well as the test length, increase the produced mass of coke, which also depends on the process temperature. As stated above, the residence time has an impact on coking rate. Thus, a linear regression (in the original coordinates system) is applied on the figure 10, which takes all these parameters into account. The vertical bars present an accuracy of $10^{-3}$. This new relationship is interesting to monitor the coke or to predict it, depending on the test conditions. This could be useful for both experimental and industrial needs.

The effect of operating pressure is difficult to analyse because it cannot be dissociated from other parameters. Indeed, when increasing the pressure, the density increases and for a given mass flow rate, this corresponds to a decrease of flow velocity, thus an increase of residence time. The thermal exchanges are also modified due to hydraulic variations. Nevertheless, it has been noticed during our tests that increasing the pressure, and in particular under supercritical state, favours the formation of coke. This is due to the increasing residence time. Clark and Subramaniam [66] recommend to work under supercritical pressure to limit the carbon deposit but this may only correspond to their study about oxidative coke. Other pyrolysis results are available in previous paper [67], in which the effects of supercritical and subcritical conditions are analysed.

\subsection{Coke detection methods for real-time and onboard monitoring application}


It has been shown how coke formation can appear during the pyrolysis process and this coke has been characterized. Even if it should not be as important on the SCRamjet engine as it is on the experimental test bench, it is preferable to have a method to monitor it at our disposal. For two different test cases, we observe the pressure losses along the one meter long reactor (Figure 11). The final sudden increase in lost pressure corresponds to the complete jamming up of the channel. The way it jams up is as follows: due to coke formation, the particles aggregates raise a significant size. This produces a first jamming up. With the upstream pressure increase, the jamming is then evacuated further in the reactor, or at the outlet. This first aggregates sticks to another one and intensifies the filling up. The pressure needed to blow it has to be higher and the same is reproduced several times until the pressure cannot remove the aggregates. This can be seen on the figure 11 . The reactor is then completely jammed by coke. The pressure losses are thus singular and not regular. This way of coke jamming up confirms previous observation during the coke formation. The coking process is heterogeneous; otherwise, the pressure loss should increase regularly until the complete filling up of the channel.

Another clue justifies the heterogeneity of the carbon deposit : the coke has not been observed on the entire surface of the reactor but mainly in the hottest part. Indeed, infrared camera (Flir Systems, Thermacam S45) has been used on a stainless steel reactor just after taking it down; because it is not possible to observe it inside the furnace. The hottest part of the reactor is initially the central one, where the furnace temperature is maximum. But this is also the part that is the coldest one after few minutes of cooling by natural convection. This particularity is due to the insulation effect of the coke. The parts of the reactor with the maximum transient thermal gradient are the one with coke deposits. This corresponds to the central part of the channel. It shows that the coke is formed heterogeneously along the process, depending on the temperature.

Considering the thermal insulation effect of the coke, it is possible to monitor its presence inside the fluid flow. Indeed, during a test of about one hour, the fluid temperature and pressure have been measured directly inside the fluid, at the reactor outlet, with K-type and R-type thermocouples of $1.5 \mathrm{~mm}$ diameter (Figure 12). Two parts of the test correspond to a pressure decrease by mean of downstream valve opening (from $1800 \mathrm{~s}$ to $2000 \mathrm{~s}$ and from $2600 \mathrm{~s}$ to $2700 \mathrm{~s}$ ), which follows a specific evolution of the fluid temperature. Between $1000 \mathrm{~s}$ and $1800 \mathrm{~s}$ (such as between $2200 \mathrm{~s}$ and $2600 \mathrm{~s}$ ), we observe a strong decrease of the temperature whereas the pressure remains almost constant. Because the pressure loss does 
not increase (around $2.10^{3} \mathrm{~Pa}$ ), the observed trend is due to the coke thermal insulation. The thermocouple inserted in the fluid flow corresponds to a stop point for the flow, where the coke can stick to this surface. The more the deposit increases, the more the measured temperature decreases, without effect on pressure loss. This explains why the temperature of the fluid decreases during a test and why a brutal pressure change corresponds to a temperature increase because it unsticks the deposit.

Depending on the jamming up intensity, the temperature decrease could be difficult to observe during the test because the reactor can be filled up very quickly for some test configurations. This complete jamming up is also accompanied by a temperature decrease but this is not due to the thermal insulation on the thermocouple but only because the fluid does not circulate in the channel (Figure 13).

The coke insulation effect could also be observed on the reactor surface because it should decrease the thermal exchange between the hot reactor and the fluid. The more carbon deposit on the surface there is, the lower is the fluid temperature. Nevertheless, this phenomenon seems to be too difficult to observe in the test configuration compared to the other strong phenomena. The monitoring of the pressure loss and of the fluid temperature could be a relevant parameter to propose a method applicable to onboard hypersonic flight for real-time management of the coking activity. This is a first step before a further one, which could consist in setting up a coking management strategy to reduce the coke deposit or to eliminate it during the cooling process.

\section{Conclusion}

In the framework of the COMPARER project, an experimental test bench has been settled to study hydrocarbon pyrolysis under potentially supercritical conditions in transient and stationary states. The ndodecane pyrolysis is accompanied by the formation of light hydrogenated species, such as hydrogen and methane, and by poorly hydrogenated coke. The coking activity appears to be a real problem because of the complete jamming up of the chemical reactors. Coke study is not the aim of the COMPARER project but it is required to analyse the reasons of this carbon deposit and to characterise it in order to propose monitoring methods suitable for the experimental bench such as for the hypersonic vehicle. In this paper, we presented for $316 \mathrm{~L}$ stainless steel, low carbon steel and titanium reactors three types of coke : pyrolytic, catalytic and asphaltic. Thanks to SEM visualisation, EDS, X-ray and FTIR analysis in particular, different kinds of coke with aggregates or shaving forms have been found. A way of formation 
has been proposed for each type of deposit and this is in agreement with various observations during the test and with other studies in literature. The catalytic and asphaltic cokes, largely observed on the experimental bench, should not be a problem for the SCRamjet engine whereas the pyrolytic one should still be present. The maximum size of the coke particles is shown to be lower than the minimal crosssection in the system, such as the injector. The coke has been characterised. Its density, its porosity and its permeability have been evaluated to determine, for example, where the fluid would flow if the coke appeared (in the channel or directly through the porous wall).

A relationship has been established between the coking rate and the residence time in particular. When decreasing the residence time, the coking activity could decrease but this also depends on various other parameters such as the process temperature. Methane appears to be a good indicator for gain of mass as far as coke is concerned. The heat flux applied on the fluid favours the coke formation, as well as the residence time, the fluid pressure, the length of the test and the quantity of hydrocarbon used during the test, the catalytic effect of the reactor and the decrease of the Reynolds number.

A temperature decrease due to the thermal insulation effect of coke appears when measuring the fluid temperature at the reactor outlet. Furthermore, sudden strong pressure losses are observed during the jamming up process. These parameters could be monitored during the pyrolysis of hydrocarbon to evaluate the coking activity. No specific action is proposed in case of coking but proposing a measurement method is the first step to do so.

For a further study of coking activity, some parameters should be analysed in details and in particular the following ones: the pressure, the Reynolds number, the catalytic effect and the presence of initially dissolved oxygen. The thermal insulation effect of the coke should also be investigated because it could change the dynamics of heat transfer in the SCRamjet cooling system.

\section{Acknowledgements}

The authors would like to give sincere thanks to JC Hargé and G Abraham for their support on this project and to P Broguy for her help involving the English writing. The present work has been carried out with the contribution of the "Conseil Général du Cher (18)", of the "Conseil Régional du Centre", of the FRED, of the FEDER, of the FSE (European Union Special Funding) and of MBDA-France. The good evolution of the COMPARER project was made possible thanks to the contribution of Y. Parmantier, who is in charge of the project and the coordinator of the "Pôle Capteurs et Automatismes" of Bourges. 


\section{References}

[1] Fry RS. A Century of Ramjet Propulsion Technology Evolution. Journal of Propulsion and Power 2004; Vol. 20, No. 1, pp. 27-58.

[2] McClinton CR. X-43 SCRamjet Power Breaks the Hypersonic Barrier Dryden Lectureship in Research for 2006. AIAA 2006; 1.

[3] Andrews EH. SCRamjet Development and Testing in the United States. AIAA 2001; 1927.

[4] Curran ET. SCRamjet Engines: The First Forty Years. Journal of Propulsion and Power 2001; Vol. 17, No. 6, pp. 1138-1148.

[5] Falempin F. High-Speed Airbreathing Propulsion: French Activities. AIAA 2002; 5232.

[6] Falempin F, Serre L. LEA Flight Test Program - Status in 2004. 40th AIAA/ASME/SAE/ASEE Joint Propulsion Conference And Exhibit 2004; AIAA-2004-3344.

[7] Shikhman YM, Vinogradov VA, Yanovski LS, Stepanov VA, Shlyakotin VE, Pen'kov SN. The Demonstrator of Technologies - Dual Mode SCRAMJET on Hydrocarbon Endothermic Fuel. AIAA $2001 ; 1787$.

[8] Boselli L, Giraudo T, Massot A, and Talbot B. Dual-Fuel Advanced High-Speed Ramjets. AIAA $2002 ; 5214$.

[9] Bouchez M, Beyer S, Cahuzac G. Ptah-Socar Fuel-Cooled Composite Materials Structure for Dual-Mode Ramjet and Liquid Rocket Engines. 40th AIAA/ASME/SAE/ASEE Joint Propulsion Conference and Exhibit; AIAA-2004-3653.

[10] Bouchez M, Beyer S. Ptah-Socar Fuel-Cooled Composite Materials Structure for Dual-Mode Ramjet and Liquid Rocket Engines - 2005 Status. 13th AIAA/CIRA International Space Planes and Hypersonics Systems and Technologies; AIAA 2005-3434.

[11] Beyer S, Schmidt S, Peres P, Bouchez M. Advanced Ceramic Matrix Composite Materials for Current and Future Propulsion System Applications. 41st AIAA/ASME/SAE/ASEE Joint Propulsion Conference \& Exhibit; AIAA 2005-3644.

[12] Townend TH. Domain of the SCRamjet. Journal of Propulsion and Power 2001; Vol. 17, No. 6, pp. $1205-1213$. 
[13] Powell OA, Edwards JT, Norris RB, Numbers KE, Pearce JA. Development of HydrocarbonFueled SCRamjet Engines: The Hypersonic Technology (Hytech) Program. Journal of Propulsion and Power 2001; Vol. 17, No. 6, pp. 1170-1176.

[14] Edwards T, Meyer ML. Propellant Requirements For Future Aerospace Propulsion Systems. 38th AIAA/ASME/SAE/ASEE Joint Propulsion Conference \& Exhibit; AIAA 2002-3870.

[15] Huang H, Sobel DR, Spadaccini LJ. Endothermic Heat-Sink of Hydrocarbon Fuels for SCRamjet Cooling. 38th AIAA/ASME/SAE/ASEE Joint Propulsion Conference \& Exhibit; AIAA 2002-3871.

[16] Daniau E, Bouchez M, Bounaceur R, Battin-Leclerc F, Marquaire PM, Fournet R. Contribution to SCRamjet Active Cooling Analysis Using N-Dodecane Decomposition Model as a Generic Endothermic Fuel. 12th AIAA International Space Planes and Hypersonic Systems and Technologies; AIAA-20036920.

[17] Thomas SR, Guy RW. Increase Capabilities of the Langley Mach 7 SCRamjet Test Facility. AIAA $1982 ; 1240$.

[18] Voland RT, Huebner LD, Mcclinton CR. X-43a Hypersonic Vehicle Technology Development. Acta Astronautica 2006; Vol. 59, Nos. 1-5, pp. 181-191.

[19] Kanda T. Study of an Airframe-Integrated SCRamjet Engine System. AIAA 2000; 3705.

[20] Wassel AT, Lssacci F, Van Griethuysen V. An Integrated Modelling Approach for Hypersonic Aircraft Thermal Management. AIAA 1995; 6022.

[21] Benay R, Chanetz B, Délery J. Code Verification/Validation with Respect to Experimental Data Banks. Aerospace Science And Technology 2003; 7:239-262.

[22] Mitani T, Ueda S, Tani K, Sato S, Miyajima H, Matsumoto M, Yasu S. Validation Studies of SCRamjet Nozzle Performance. Journal of Propulsion and Power 1993; Vol. 9, No. 5.

[23] Sicard M, Raepsaet B, Ser F, Masson C. Thermal Decomposition of a Model Endothermic Fuel. 14th AIAA/AHI Space Planes and Hypersonic Systems and Technologies Conference; AIAA-2006-7974. [24] Edwards T, DeWitt MJ, Shafer L, Brooks D, Huang H, Bagley SP, Oña JO, Wornat MJ. Fuel Composition Influence on Deposition in Endothermic Fuels. 14th AIAA/AHI Space Planes and Hypersonic Systems and Technologies Conference; AIAA-2006-7973. 
[25] Daniau E, Bouchez M, Herbinet O, Marquaire PM, Gascoin N, Gillard P. Fuel reforming for SCRamjet thermal management and combustion optimization. 13th AIAA/CIRA Hypersonic Conference; AIAA 2005-3403.

[26] Wade AS, Ingham DB, Kyne AG, Mera NS, Pourkashanian M, Wilson CW. Optimisation of the Arrhenius parameters in a semi-detailed mechanism for jet fuel thermal degradation using a genetic algorithm. Proceedings of ASME Turbo Expo 2004: Land, sea and air; GT-2004-53367.

[27] Morris R, Miller J. Fuel Deoxygenation and Aircraft Thermal Management. 4th International Energy Conversion Engineering Conference and Exhibit (IECEC); AIAA-2006-4027.

[28] Weill J, Broutin P, Billaud F, Gueret C. Coke Formation during Hydrocarbons Pyrolysis _ Part One: Steam Cracking. Oil \& Gas Science and Technology, Revue de l'Institut Français du Pétrole, 1992; Volume 47, nº4, p. 537-549.

[29] Ziegler-Devin I., Fournet R., Marquaire P.M., Pyrolysis of propane for CVI of pyrocarbon Part III: Experimental and modeling study of the formation of pyrocarbon, J. Anal. Appl. Pyrolysis 79 (2007) $268-277$.

[30] Cai H, Krzywicki A, Oballa MC. Coke formation in steam crackers for ethylene production. Chemical Engineering and Processing 2002; 41:199-214.

[31] I Suelves, MJ Lázaro, R Moliner, BM Corbella, JM Palacios. Hydrogen production by thermo catalytic decomposition of methane on Ni-based catalysts: influence of operating conditions on catalyst deactivation and carbon characteristics. International Journal of Hydrogen Energy 2005; Vol 301555 1567.

[32] Yue C, Watkinson AP, Lucas JP, Chung KH. Incipient coke formation during heating of heavy hydrocarbons. Fuel 2004; 83:1651-1658.

[33] Gentzis T, Rahimi PM. A microscopic approach to determine the origin and mechanism of coke formation in fractionation towers. Fuel 2003; 82:1531-1540.

[34] Lieberman NP. Shot Coke: its origins and prevention. O\&GJ, July 8, 1985. pp45.

[35] García-Dopico M, García A, Santos García A. Modelling coke formation and deactivation in a FCCU. Applied Catalysis A: General 2006; 303: 245-250.

[36] Minicucci D, Zou XY, Shaw JM. The impact of liquid-liquid-vapour phase behaviour on coke formation from model coke precursors. Fluid Phase Equilibria 2002; 194-197 :353-360. 
[37] Fournier G, Joly JF. Reformage catalytique. Techniques de l'Ingénieur; J5915.

[38] Raimbault C, Lefebvre G. Vapocraquage des hydrocarbures. Techniques de l'Ingénieur; J5460.

[39] Holmes SM, Garforth A, Dwyer J. Pyrolysis GC-MS study of external coke composition on HZSM-5 zeolite catalysts. Thermochimica Acta 1997; 294:57-64.

[40] Chua YT, Stair PC. An ultraviolet Raman spectroscopic study of coke formation in methanol to hydrocarbons conversion over zeolite H-MFI. Journal of Catalysis 2003; 213:39-46.

[41] Guisnet M, Magnoux P, Organic chemistry of coke formation. Applied Catalysis A: General 2001; 212:83-96.

[42] Doka Nassionou GA, Magnoux P, Guisnet M. Coke formation on HFAU and HEMT zeolites. Influence of the reaction temperature and propene pressure. J. Chim. Phys. 1999; Vol. 96, N², pp. 303318.

[43] McPherson LJ. Causes of FCC Reactor Coke Deposits Identified. O\&GJ, September 10, 1984; pp139.

[44] Antonini G. Traitement thermique des déchets, processus thermochimiques. Techniques de l'Ingénieur; G2050.

[45] Souza BA, Matos EM, Guirardello R, Nunhez JR. Predicting coke formation due to thermal cracking inside tubes of petrochemical fired heaters using a fast CFD formulation. Journal of Petroleum Science and Engineering 2006; 51:138-148.

[46] Quintana-Solórzano R, Thybaut JW, Marin GB, Lødeng R, Holmen A. Single-Event MicroKinetics for coke formation in catalytic cracking. Catalysis Today 2005; 107-108 : 619-629.

[47] Schabron JF, Pauli AT, Rovani JF Jr. Residua coke formation predictability maps. Fuel 2002; $81: 2227-2240$.

[48] Shubo F, Liming S, Qiangkun L. A study on coke deposition and coking inhibitors during AGO pyrolysis in pulsed micro-reactor system. Journal of Analytical and Applied Pyrolysis 2002; 65:301-312.

[49] Dieckmann GH, Moir ME. Process for reducing coke formation in hydrocarbon processing by application of radio frequency electromagnetic radiation utility. American Patent $\mathrm{N}^{\circ}$ 6790547, 2004; acceded in August, the $10^{\text {th }} 2006$ on http://www.freepatentsonline.com/6790547.html.

[50] Gascoin N, Gillard P, Dufour E, Touré Y. Validation of transient cooling modelling for hypersonic application. Journal Of Thermophysics And Heat Transfer 2007; Vol. 21 No. 1 86-94. 
[51] Sholl DS, Bhatia B. Ab Initio Studies of Coke Formation on Ni Catalysts During Methane Reforming. University Coal Research, Institutions Contractor Review Meeting, June 3, 2003.

[52] Grace-Chan KY, Senkan S. Suppression of Coke Formation in the Steam Cracking of Alkanes: Ethane and Propane. Industrial \& Engineering Chemistry Research 1998; 37, 901-907.

[53] Gascoin N, Gillard P, Bernard S, Abraham G, Bouchez M, Daniau E and Touré Y. Measurements for fuel reforming for scramjet thermal management and combustion optimization : status of the COMPARER project. 14th AIAA/AHI Space Planes and Hypersonic Systems and Technologies Conference; AIAA-2006-8005.

[54] VZ Mordkovich, EA Dolgova, AR Karaeva, DN Kharitonov, IA Maslov, AA Kamenev, VF Tretjakov. Synthesis of carbon nanotubes by catalytic conversion of methane: Competition between active components of catalyst. Carbon 2007; Vol 45 62-69.

[55] K Asami, K Hashimoto. Importance of initial surface film in the degradation of stainless steels by atmospheric exposure. Corrosion Science 2003; Vol 45 2263-2283.

[56] A Moronta, M E Troconis, E Gonzalez, C Moran, J Sanchez, A Gonzalez, J Quinonez. Dehydrogenation of ethylbenzene to styrene catalyzed by Co, Mo and CoMo catalysts supported on natural and aluminum-pillared clays Effect of the metal reduction. Applied Catalysis A: General 2006, Vol 310 199-204.

[57] K A Magrini-Bair, S Czernik, R French, Y O Parent, E Chornet, D C Dayton, C Feik, R Bain. Fluidizable reforming catalyst development for conditioning biomass-derived syngas. Applied Catalysis A: General 2007; Vol 318 199-206.

[58] E Diaz, S Ordonez, A Vega, J Coca. Evaluation of different zeolites in their parent and protonated forms for the catalytic combustion of hexane and benzene. Microporous and Mesoporous Materials 2005; Vol 83 292-300.

[59] X Gao et al. Characterization of oxide films grown on 316L stainless steel exposed to H2O2containing supercritical water. J. Supercrit. Fluids 2007; doi:10.1016/j.supflu.2006.12.020.

[60] Z Yang et al. High temperature oxidation/corrosion behavior of metals and alloys under a hydrogen gradient. International Journal of Hydrogen Energy 2006; doi: 10.1016/j.ijhydene.2006.08.056.

[61] JA Wharton, RJK Wood. Influence of flow conditions on the corrosion of AISI 304L stainless steel. Wear 2004; Vol 256 525-536. 
[62] S Seal, K Sapre, A Kale, V Desai, M Gopal, P Jepson. Effect of multiphase flow on corrosion of C-steel in presence of inhibitor: a surface morphological and chemical study. Corrosion Science 2000; Vol 42 1623-34.

[63] TM Hayward, IM Svishchev, RC Makhija. Stainless steel flow reactor for supercritical water oxidation: corrosion tests. J. of Supercritical Fluids 2003; Vol 27 275-281.

[64] Gascoin N. Etude et mesure de paramètres pertinents dans un écoulement réactif. Ph.D. Thesis 2006; available at http://tel.archives-ouvertes.fr/tel-00128418 Orleans University 30/11/06 Bourges.

[65] A Shamsi, J P Baltrus, J J Spivey. Characterization of coke deposited on Pt/alumina catalyst during reforming of liquid hydrocarbons. Applied Catalysis A: General 2005; Vol 293 145-152.

[66] M C Clark, B Subramaniam. Kinetics on a Supported Catalyst at Supercritical, Nondeactivating Conditions. AIChE Journal July 1999; Vol. 45 No. 7 1559-65.

[67] N. Gascoin, P. Gillard, S. Bernard, E. Daniau, M. Bouchez, Pyrolysis of Supercritical Endothermic Fuel: Evaluation for Active Cooling Instrumentation, International Journal of Chemical Reactor Engineering, Vol. 6, Article A7, Ed. The Berkeley Electronic Press, 2008. 


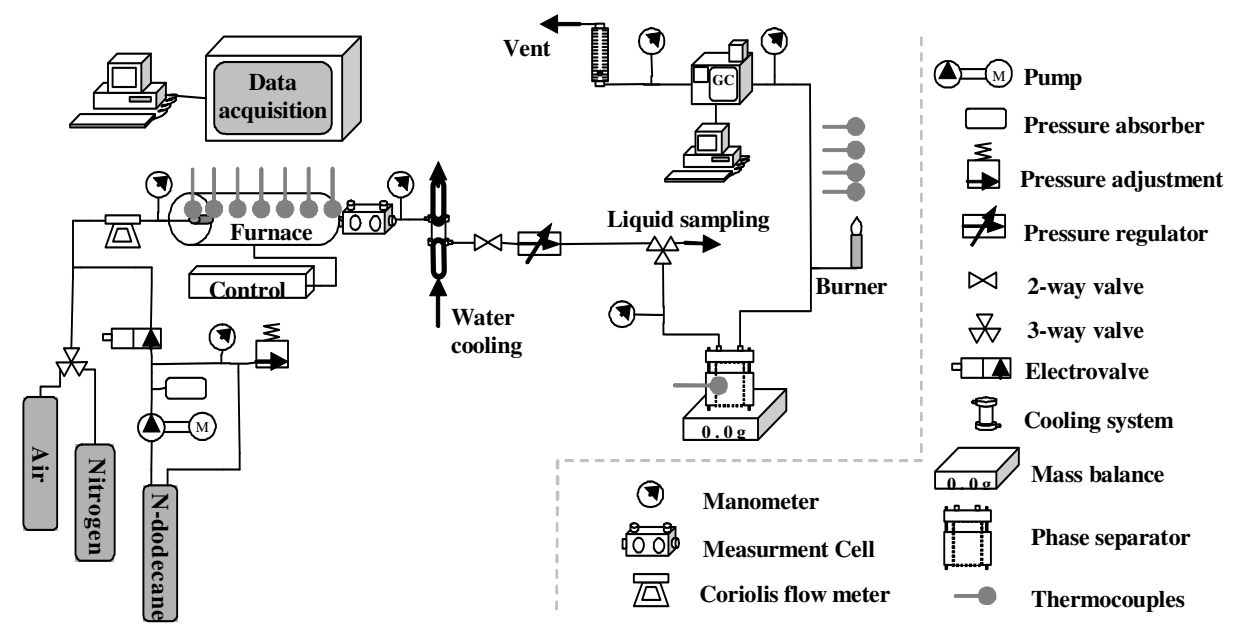

Figure 1. Simplified sketch of the COMPARER fuel pyrolysis test bench 

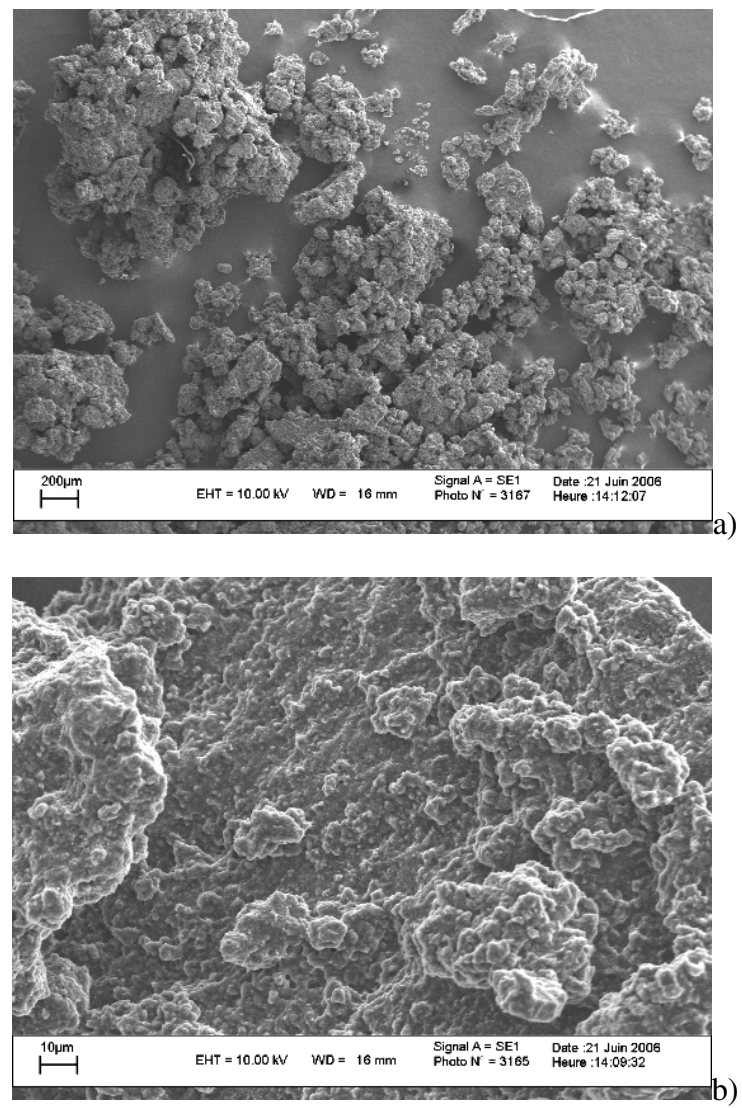

Figure 2. Sub-millimetric coke aggregates found in stainless steel reactor (a) and Micrometric particles constituting the coke aggregates on stainless steel reactor (b). 


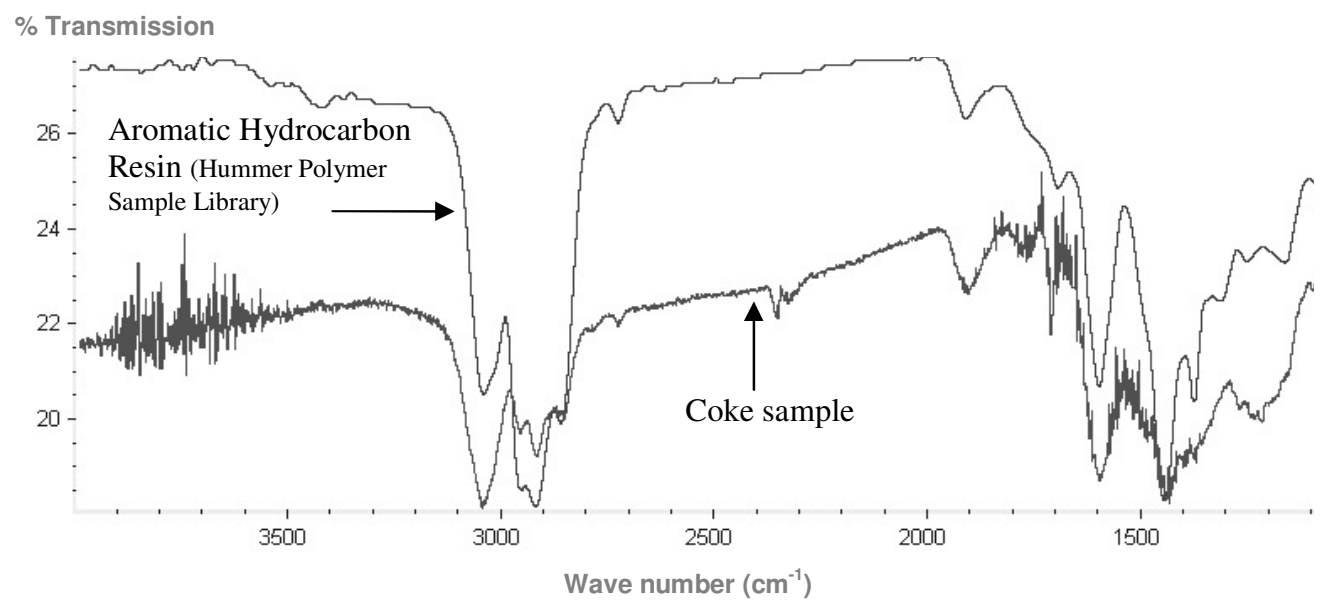

a)

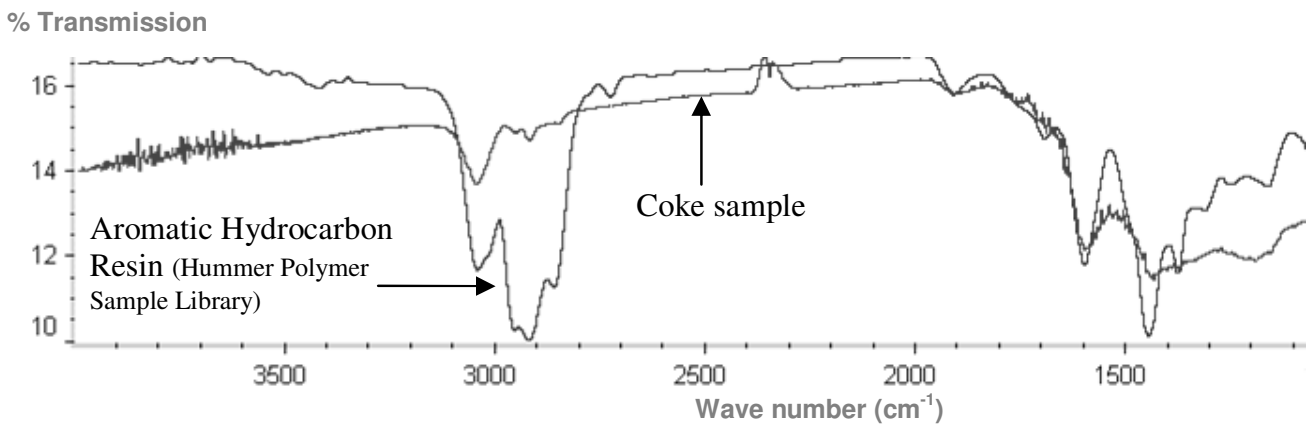

b)

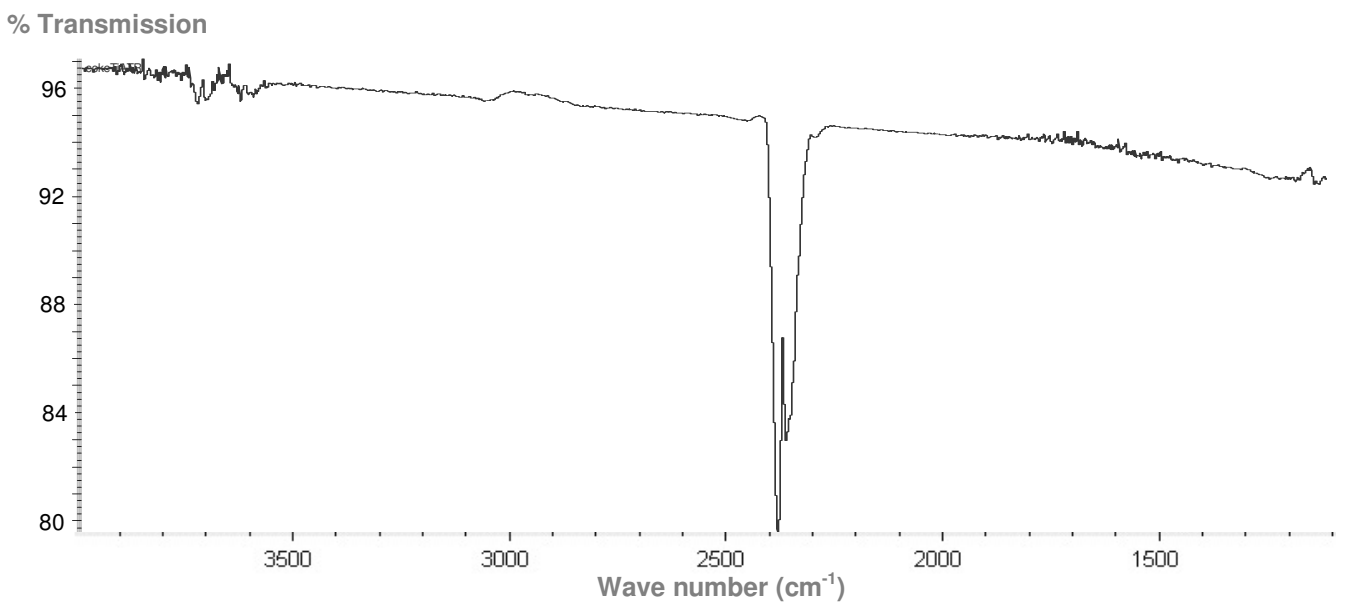

c)

Figure 3. FT-IR analyses of coke obtain for stainless steel reactor (a), low carbon steel reactor (b) and Titanium reactor (c). Comparisons are given with Aromatic Hydrocarbon Resin found in the literature. 


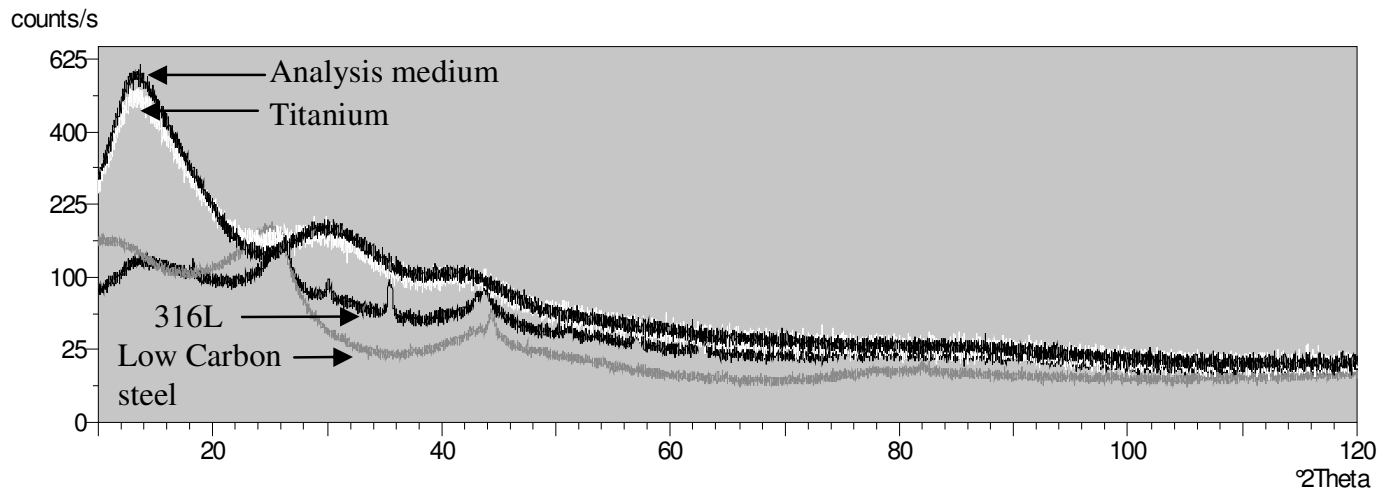

Figure 4. DRX analyses of coke obtained for three different natures of chemical reactors. 


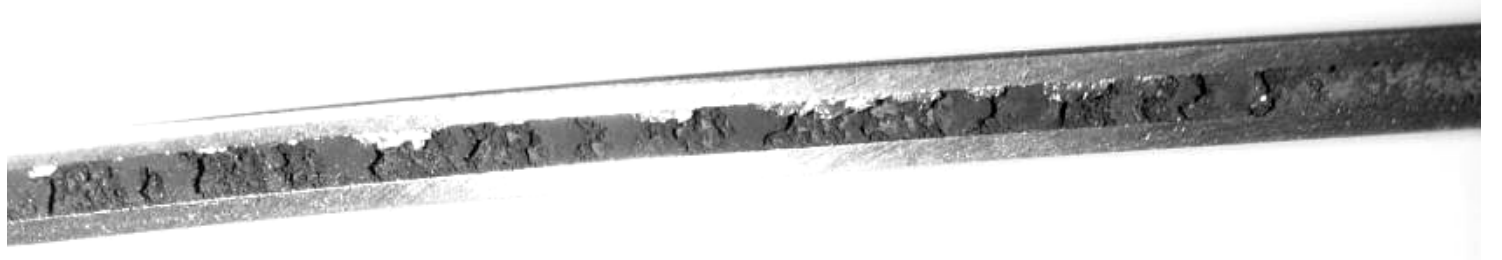

Figure 5. Stainless steel reactor, of $1.8 \cdot 10^{-3} \mathrm{~m}$ inner diameter, jammed by coke. 


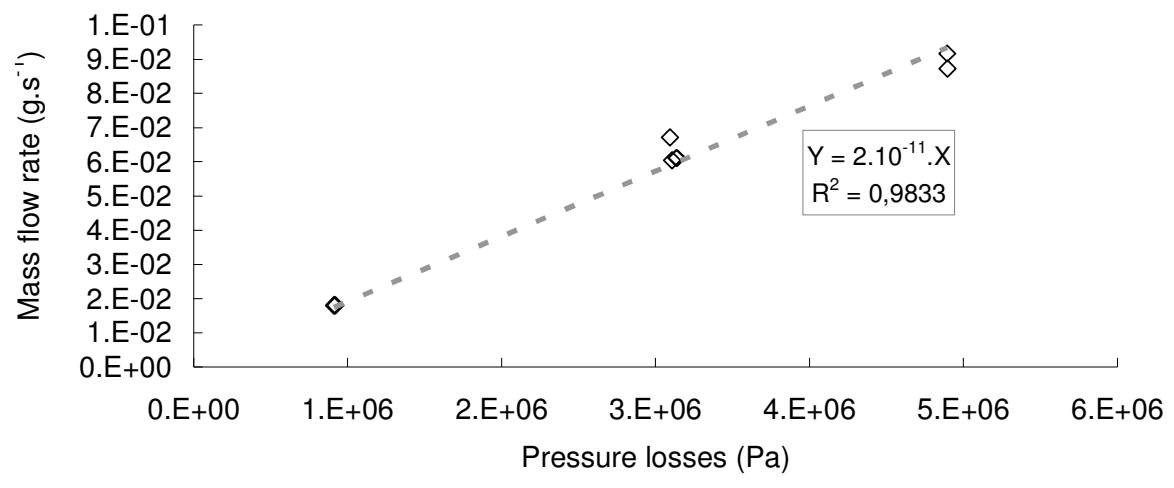

Figure 6. Pressure losses measured on jammed stainless steel reactor for coke permeability determination. 

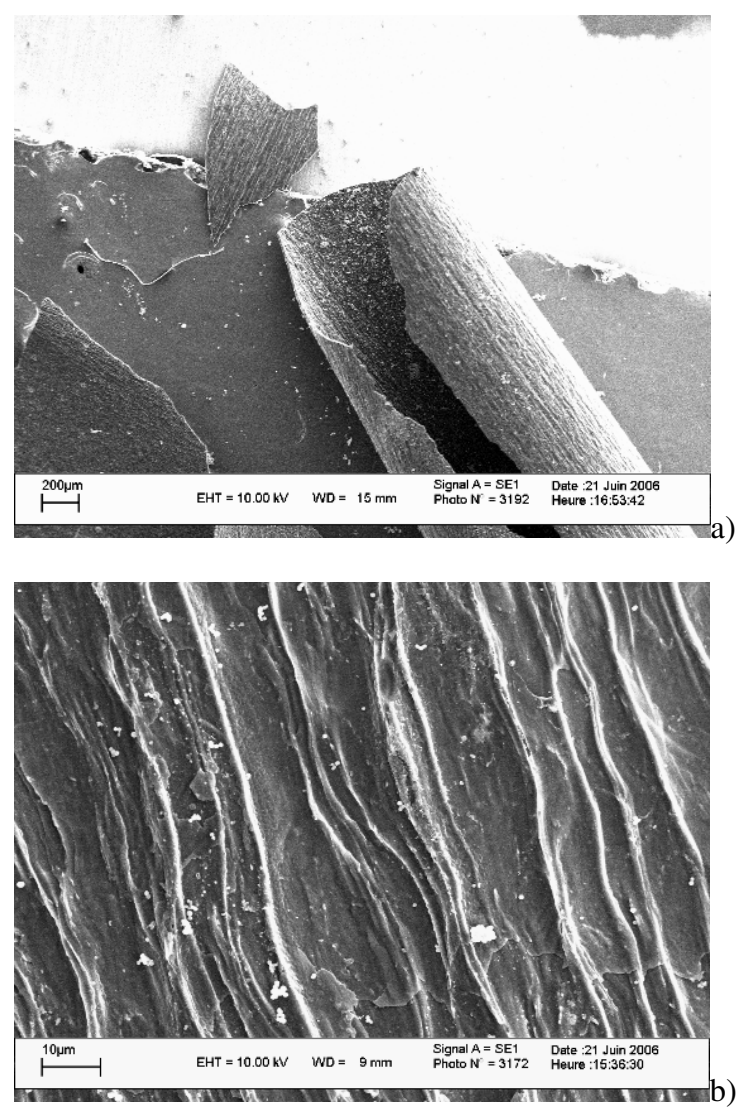

Figure 7. Dry coke shavings found on low carbon steel reactor (a) and ridges found on the external surface of coke shavings due to lamination process for reactor conception (b). 


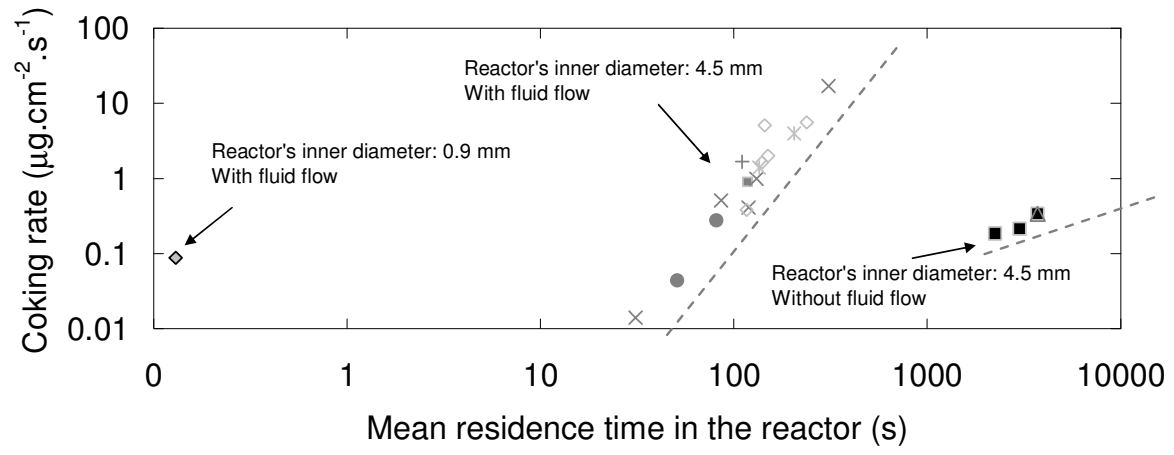

Figure 8. Residence time dependence of coking activity for all the conducted tests. 


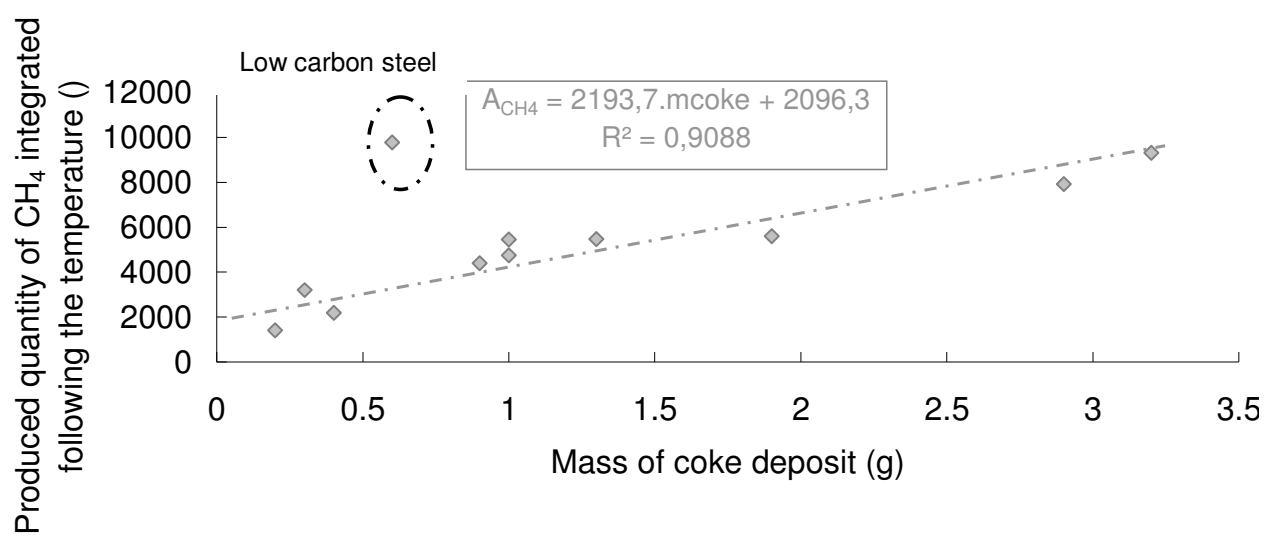

Figure 9. Relationship between coke formation and methane production. 


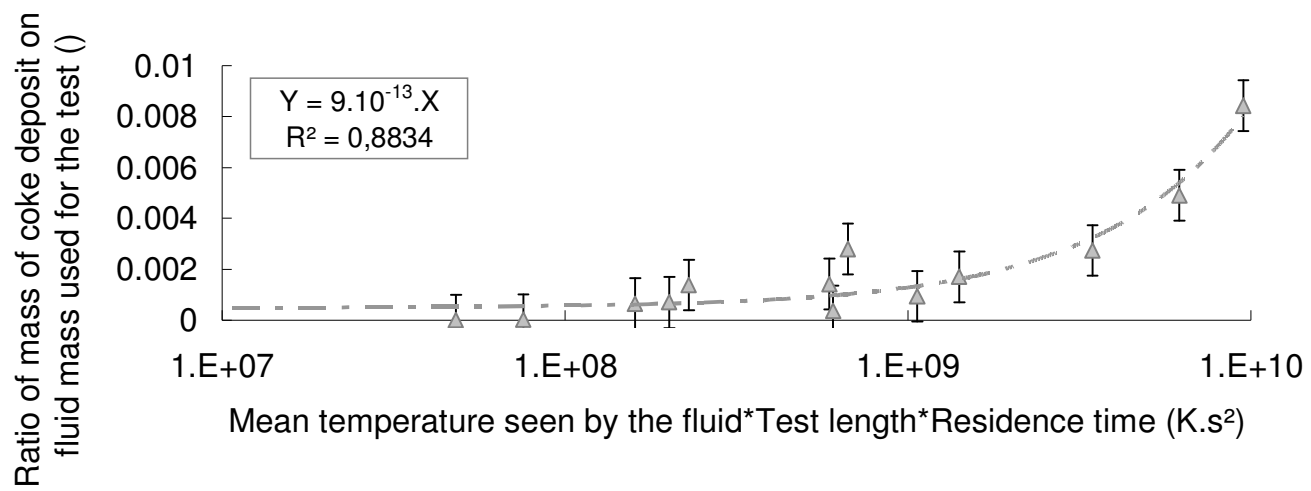

Figure 10. Relationship between coke formation and various parameters such as the residence time. 


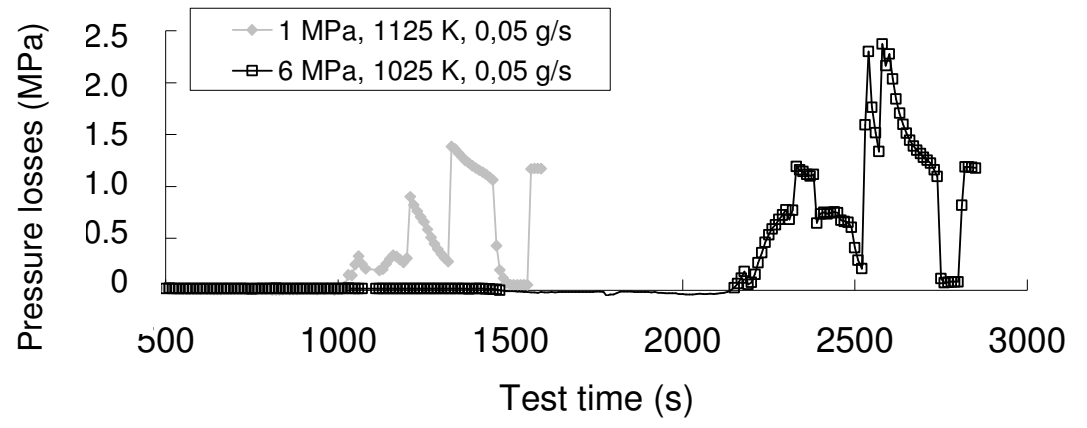

Figure 11. Typical measures of pressure losses during reactor jamming up by coke. 


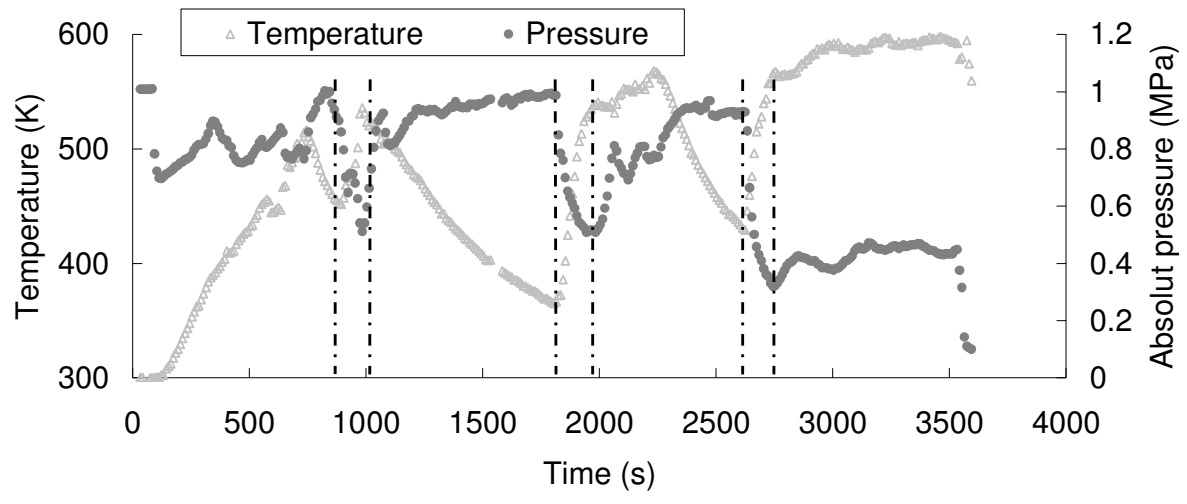

Figure 12. Thermal insulation effect of coke on thermocouple without variation of pressure in the system. 


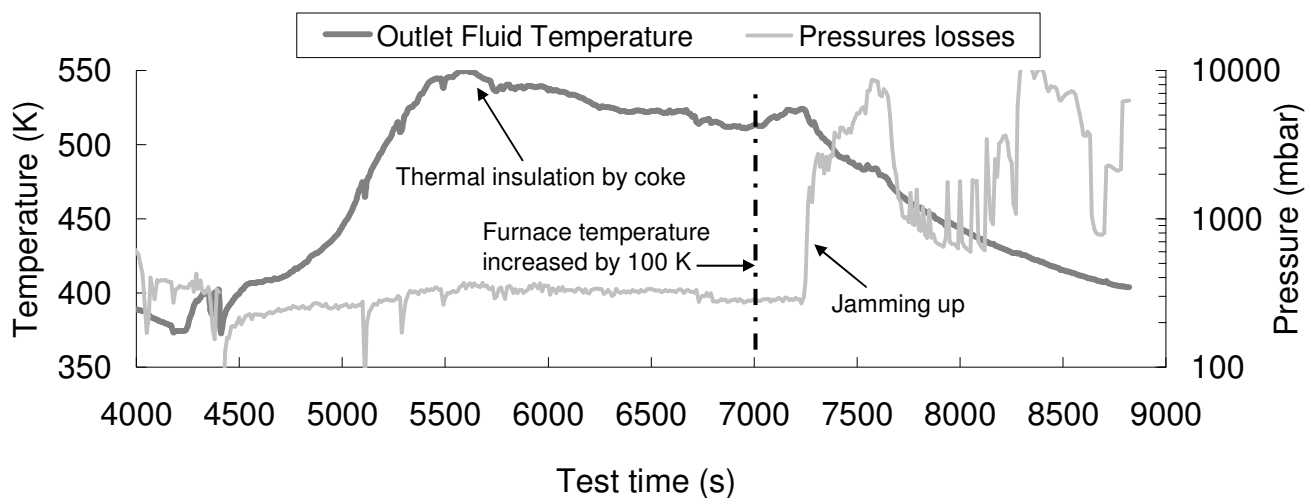

Figure 13. Monitoring by temperature of slow coking activity followed by sudden jamming up; pressure losses behaviour. 
Table 1. Geometric characteristics of pyrolysis reactors.

\begin{tabular}{ccccc}
\hline \hline & Initial length of the reactor $(\mathrm{m})$ & Inner Diameter $(\mathrm{mm})$ & External diameter $(\mathrm{mm})$ & $\begin{array}{c}\text { Initial } \\
\text { mass }(\mathrm{g})\end{array}$ \\
\hline 316L & 100 & 4.5 & 6.35 & 213 \\
low carbon & 112 & 4.5 & 6.35 & 229 \\
Ti (Grade2) & 101 & 4.5 & 6.35 & 74 \\
\hline \hline
\end{tabular}


Table 2. Chemical compositions of pyrolysis reactors.

\begin{tabular}{ccccccccccccc}
\hline \hline & Al & $\mathrm{C}$ & $\mathrm{Cr}$ & $\mathrm{Fe}$ & $\mathrm{Mn}$ & $\mathrm{Mo}$ & $\mathrm{Ni}$ & $\mathrm{P}$ & $\mathrm{S}$ & $\mathrm{Si}$ & $\mathrm{Ti}$ \\
\hline $316 \mathrm{~L}$ & - & 0.014 & 17.36 & Bal. & 1.57 & 2.53 & 13.96 & - & 0.006 & 0.5 & - \\
& & & & & & & & & & & \\
low carbon" & $<0.5$ & 0.2 & $<0.5$ & Bal. & $\# 1.5$ & $<0.5$ & $<0.5$ & $<0.5$ & $<0.5$ & $<0.5$ & - \\
Ti (Grade2) & - & - & - & - & - & - & - & - & - & - & 99.5 \\
\hline \hline
\end{tabular}

Typical composition 
Figure 1. Simplified sketch of the COMPARER fuel pyrolysis test bench

Figure 2. Sub-millimetric coke aggregates found in stainless steel reactor (a) and Micrometric particles constituting the coke aggregates on stainless steel reactor (b).

Figure 3. FT-IR analyses of coke obtain for stainless steel reactor (a), low carbon steel reactor (b) and Titanium reactor (c). Comparisons are given with Aromatic Hydrocarbon Resin found in the literature.

Figure 4. DRX analyses of coke obtained for three different natures of chemical reactors.

Figure 5. Stainless steel reactor, of $1.8 .10^{-3} \mathrm{~m}$ inner diameter, jammed by coke.

Figure 6. Pressure losses measured on jammed stainless steel reactor for coke permeability determination.

Figure 7. Dry coke shavings found on low carbon steel reactor (a) and ridges found on the external surface of coke shavings due to lamination process for reactor conception (b).

Figure 8. Residence time dependence of coking activity for all the conducted tests.

Figure 9. Relationship between coke formation and methane production.

Figure 10. Relationship between coke formation and various parameters such as the residence time.

Figure 11. Typical measures of pressure losses during reactor jamming up by coke.

Figure 12. Thermal insulation effect of coke on thermocouple without variation of pressure in the system.

Figure 13. Monitoring by temperature of slow coking activity followed by sudden jamming up; pressure losses behaviour.

Table 1. Geometric characteristics of pyrolysis reactors.

Table 2. Chemical compositions of pyrolysis reactors. 